\title{
Risk Factors For Readmission Among Patients Receiving Outpatient Parenteral Antimicrobial Therapy; A Retrospective Cohort Study
}

\section{Sabrine Douiyeb}

Amsterdam UMC - location VUmc https://orcid.org/0000-0002-2533-4627

Jara R. de la Court ( $\nabla$ j.delacourt@amsterdamumc.nl )

Amsterdam UMC - location VUmc

Bram Tuinte

Amsterdam UMC - location VUmc

Ferdi Sombogaard

Amsterdam UMC - location VUmc

Rogier P. Schade

Amsterdam University Medical Center

Marianne Kuijvenhoven

Amsterdam UMC - location VUmc

Tanca Minderhoud

Amsterdam UMC - location VUmc

Kim C. Sigaloff

Amsterdam UMC - location VUmc

\section{Research Article}

Keywords: antimicrobial, retrospective, therapeutic, aminoglycosides

Posted Date: December 1st, 2021

DOI: https://doi.org/10.21203/rs.3.rs-1104099/v1

License: (c) (i) This work is licensed under a Creative Commons Attribution 4.0 International License.

Read Full License

Version of Record: A version of this preprint was published at International Journal of Clinical Pharmacy on February 14th, 2022. See the published version at https://doi.org/10.1007/s11096-022-01379-7. 


\section{Abstract}

Background: In the Netherlands, home treatment with intravenous antimicrobial therapy is a relatively new concept. Although several studies have shown that outpatient parenteral antimicrobial therapy (OPAT) can be administered safely, people receiving antimicrobials at home remain at risk for adverse events, including readmission.

Objectives: The aim of our retrospective study is to identify risk factors for readmission in patients discharged with OPAT.

Method: Retrospective cohort study during a period of January 2016 - December 2018. Patients, age $>18$ years, discharged with OPAT were included. Variables collected consisted of baseline demographics, complications, readmission within 30 days and treatment failure. Multivariate logistic regression analysis was performed to identify risk factors for readmission.

Results: A total of 247 patients were included; the most common reason for OPAT was bone and joint infections (17\%). Penicillin (37\%), cephalosporin (26\%) and vancomycin/aminoglycoside (15\%) were the most commonly prescribed antimicrobials. Among the patients receiving medication subject to therapeutic drug monitoring (i.e. aminoglycosides or vancomycin), 51\% (19/37) received weekly therapeutic drug monitoring. Receiving aminoglycosides or vancomycin (adjusted OR: 2.05; $95 \% \mathrm{Cl}, 1.30$ $3.25, \mathrm{p}<0.05$ ) and infection of prosthetic material (adjusted OR: 2.92, 95\% Cl, 1.11-7.65, $\mathrm{p}<0.05$ ) were independent risk factors for readmission.

Conclusion: Although patients receiving medication subject to therapeutic drug monitoring are at higher risk of readmission, only half of the patients discharged with aminoglycosides or vancomycin were monitored according to IDSA guidelines. A specialized team in charge of monitoring OPAT-patients is likely to increase the rate of monitoring to prevent readmissions and complications.

\section{Impact Of Findings On Practice Statements}

- Discharge with vancomycin or aminoglycoside is an independent risk factor for readmission of OPATpatients

- In our setting, half of patients requiring therapeutic drug monitoring, received laboratory monitoring when discharged with OPAT.

- A specialized team in charge of monitoring OPAT-patients is likely to increase the rate of therapeutic drug monitoring and could prevent readmissions and complications.

\section{Introduction}

Ever since the introduction of outpatient parenteral antimicrobial therapy (OPAT), its application has increased[1]. OPAT can be administered when the patient is stable, but requires prolonged intravenous 
(IV) antibiotic therapy as a result of an active infection. In the past, OPAT has shown to be safe and to lead to a reduction of length of stay and subsequent decrease of costs [2,3]. Previous studies have also described a high satisfaction rate of patients treated with OPAT at home $[4,5]$. Although OPAT is usually considered safe, people receiving antimicrobials at home remain at risk for adverse events and readmission and therefore require appropriate follow-up and laboratory monitoring in the outpatient setting, when discharged with OPAT [6-9].

The Infectious Diseases Society of America (IDSA) 2018 guidelines recommend to have a specialized multidisciplinary team in place, an "OPAT-team", consisting of an infectious disease specialist or pharmacist, in charge of coordinating the OPAT-care[10]. The introduction of a dedicated OPAT-team to coordinate the care of patients receiving intravenous antibiotic therapy at home can offer several benefits. First, a specialized team can assess the appropriateness of antimicrobials prescribed on hospital discharge and perform antimicrobial stewardship interventions if necessary $[11,12]$. Second, the OPAT-team can monitor patients discharged with IV antibiotics and subsequently detect and potentially reduce adverse events and readmissions by intervening at an early stage[13-15].

Although consultation of the OPAT-team has been proposed for every patient before the initiation of OPAT, identifying patients with a high risk for readmission remains difficult. Previous studies have identified various risk factors to be associated with readmission, such as; discharge to a skilled nursing facility[7], previous hospital admission[9] and discharge with medication subject to TDM[6, 16].

The aim of this study is to identify risk factors associated with readmission in patients receiving OPAT, in a hospital without a dedicated OPAT-team. This information will be used for implementation and improvement of the OPAT-team program at a large teaching hospital in the Netherlands.

\section{Method}

\section{Ethical approval}

This study was approved by the Medical Ethical Committee (METC) of the Amsterdam UMC - location VUmc on the $15^{\text {th }}$ of December 2020. Approval reference number: 2019.208.

\section{Patient population and setting}

We performed a retrospective cohort study at the Amsterdam University Medical Center - location Vrije Universiteit Medical Center (VUmc), a 730-bed tertiary academic medical center in Amsterdam, the Netherlands. After approval of the study, a list of eligible patients discharged with OPAT in the period of January 2016 until December 2018 was generated by our hospital pharmacy. During this period a specialized OPAT team was not present in our hospital. Patients younger than 18 years of age were excluded, as were patients with missing data due to transfers to other hospitals or if hospital information was missing or if the final discharge was oral treatment. Data were collected from the electronic hospital patients records. Data was entered in the secured electronic database Castor. 


\section{Data collection, definitions and outcomes}

Variables were collected from documented notes from the electronic patient records (EPIC) and consisted of: patient demographics, comorbidities, date of admission and discharge, hospital ward, diagnosis, microbiological information, antimicrobial regimens and complications during outpatient treatment. OPAT days were calculated as the number of days between hospital discharge and the stop date of the antibiotic as noted in the patient records. Comorbidities were grouped in the following categories: diabetes mellitus, immune-compromised, malignancy, coronary heart disease and cognitive impairment. Information about the antibiotic regimen were collected and included type of received antimicrobial therapy and the start and stop date.

The primary outcome of this study was readmission within 30 days after discharge with OPAT. Risk factors for readmission were explored. Readmission was defined as readmission in the Amsterdam UMC - location VU within 30 days after discharge. Reasons for readmission and presentation at the emergency room were collected. Secondary outcomes included complications and monitoring frequency during OPAT. Complications were defined as antibiotic-related adverse drug events (ADE), line-related and non-OPAT related complications. Antibiotic-related adverse drug events consisted of decline in renal function, gastro-intestinal adverse events (loss of appetite, fatigue, malaise), hepatotoxicity, electrolyte imbalance and inadequate dosage of antimicrobial therapy (suboptimal or toxic doses). Line-related complications consisted of: mechanical issues (leakage, dislocation or dysfunction/obstruction of line of pump), line related infection and thrombosis.

The frequency of monitoring of the patient discharged with OPAT was recorded. Monitoring was defined as weekly contact with the patient consisting of any of the following; telephone contact, laboratory testing or outpatient consultation. We analyzed the monitoring frequency in patients who received weekly monitoring versus who were not weekly monitored. In patients receiving medication subject to TDM (aminoglycosides and vancomycin), the frequency of therapeutic drug monitoring and the adherence to the IDSA guidelines were collected ${ }^{[10]}$. Therapeutic drug monitoring was considered to be adequate if a weekly blood sample was obtained. Treatment failure was defined as worsening or ongoing infection resulting in a visit to the emergency room or a readmission.

\section{Statistical analysis}

Categorical variables were summarized as proportions or frequencies, whereas continuous variables were summarized by median and interquartile range. A univariate and multivariate logistic regression were performed to identify risk factors associated with readmission. Variables with a p-value $<0.20$ in univariate analysis were included the multivariable logistic regression. A p-value $<0,05$ was considered statistically significant. Data were analyzed in IBM SPSS 26.

\section{Results}

Baseline characteristics and frequency of monitoring 
A total of 347 patients were discharged with between January 2016 and December 2018. Exclusion reasons are summarized in Figure 1. A total of 247 patients were included for analysis, of which $n=27$ were readmitted (Table 1). The majority of patients was discharged from non-surgical wards $(56 \%)$. The median age was 62 years (IQR 50-72), 64\% were male. Half of the patients (50\%) had at least one comorbidity. The most prevalent indication for OPAT was osteomyelitis (17\%), followed by prosthetic infections (14\%), complicated urinary tract infections (14\%) and respiratory infections (13\%). The most frequent causative bacterial pathogen identified was Staphylococcus aureus (32\%), followed by the Pseudomonas spp. (13\%, Figure 2). The majority of patients (84\%) were discharged to receive OPAT through a PICC-line, the remaining were discharged with a peripheral infusion $(11 \%)$ or central venous line (6\%). The most common antibiotic group prescribed is penicillin (37\%), followed by cephalosporins (26\%) and vancomycin or aminoglycoside (15\%).

\section{Readmission}

Twenty-five of the 247 patients were readmitted within 30 days (10\%). The reasons for readmission and presentation at the emergency room are listed in Table 2 . The majority of patients were readmitted due to treatment failure (44\%) and line related complications (25\%). Univariate analysis found that readmitted patients were more likely to have infection of prosthetic material and were more likely to be treated with vancomycin or aminoglycosides and were more likely to be treated for a longer duration. After adjusting for confounders in multivariate analysis (age, discharge destination, gender, treatment duration, indication) discharge with vancomycin or aminoglycoside (adjusted OR: $2.05 ; 95 \% \mathrm{Cl}, 1.30-3.25, \mathrm{p}<0.05$ ) and infected prosthetic material (adjusted OR: 2.92, 95\% Cl, 1.11-7.65, $p<0.05$ ) were found to be an independent predictor for readmission.

\section{Complications}

A total of 41 patients (16\%) experienced complications during OPAT treatment. Thirty-nine percent of complications consisted of antibiotic-related adverse drug events (ADEs) and $51 \%$ of line-related complications. ADEs consisted of gastro-intestinal adverse events $(n=6)$, electrolyte imbalance $(n=3)$, nephrotoxicity $(n=4)$, which were accompanied by toxic blood serum levels $(n=4)$, hepatotoxicity $(n=1)$ and subtherapeutic blood serum levels $(\mathrm{n}=2)$.

Eight patients developed line related infections (38\%). In two cases, patients developed a line thrombosis and eleven patients experienced mechanical issues. A total of twelve patients experienced treatment failure which consisted of worsening of ongoing infection resulting in a visit to the emergency room or readmission (8\% versus $92 \%)$.

\section{Frequency of monitoring}

We assessed the frequency of monitoring in this study. A total of 57 patients were excluded from this analysis due to a OPAT duration of equal or less than 7 days, which did not require outpatient monitoring. Sixty-eight percent of the patients (129/190) were monitored on a weekly basis (see Table 3.). We analyzed the rate of complications among those with weekly monitoring versus those who were not 
weekly monitored. Therapeutic drug monitoring was performed on a weekly basis in $51 \%$ (19 out of 37 patient receiving medication requiring TDM). Only 7 patients who received weekly therapeutic drug monitoring, met the complete laboratory recommendations of the IDSA guidelines for OPAT.

\section{Discussion}

In this retrospective study we evaluated care for patients receiving OPAT, in a setting without a specialized OPAT-team in place, at a large teaching hospital in the Netherlands. Our main objective was to identify risk factors associated with readmission within 30 days after discharge. We found that patients discharged with vancomycin or aminoglycosides have a higher risk of readmission and only half of this group received TDM on a weekly base. Furthermore, infected prosthetic material was identified as a second risk factor for readmission. We found that a total $16 \%$ of the patients discharged with OPAT experienced complications.

Our first finding is in line with previous studies, which reported that patients treated with aminoglycosides [6] have a higher risk of readmission. Several studies have also found vancomycin to be a risk factor of readmission. $[8,16]$ One explanation for this finding is that aminoglycoside and vancomycin are nephrotoxic agents, which can cause kidney injury and therefore require close monitoring. Secondly, this study confirmed that infected prosthetic material to be second independent predictor for readmission. This finding has previously been described by Duggal[17], who observed that patients discharged with OPAT for prosthetic joint infections to have a high readmission rate within 12 weeks of discharge (73\%). This is the first study to identify infected prosthetic material as an independent predictor of readmission in OPAT-patients. A different study found discharge to a skilled nursing facility to be associated with a higher risk of readmission[7]. We were not able to confirm this finding in this study.

In this study we found that the majority of complications were line related (21/247). This is consistent with that of previous studies ${ }^{[11,18]}$. Surprisingly, only 16 of the $247(6 \%)$ patients were found to have antibiotic-related $A D E$ documented. Previous studies evaluating the complication rate of antibiotic-related ADE in OPAT patients observed a higher complication rate of $15-20 \%{ }^{[8]}$, with one study even describing an ADE rate of $63 \% .^{[19]}$

A possible explanation for this inconsistency may be the lack of adequate follow-up due to the retrospective nature of this study. We tried to correct for this factor by establishing the frequency of monitoring in this cohort. We observed that patients who were monitored on a weekly basis had a higher complication and readmission rate versus non-weekly monitored patients ( $23 \%$ versus $13 \%$ and $16 \%$ versus $5 \%$ ). This could imply that complications go unnoticed in patients who did not receive weekly monitoring. This hypothesis is confirmed by Huck et al(2013) ${ }^{[20]}$, which found that less frequent monitoring, defined as non-availability of recommended test results, to be independently associated with readmission. Compared to the study of Huck et al (2013) ${ }^{[20]}$, in this study a broad definition of weekly monitoring was used, namely either telephone contact, laboratory testing or outpatient consultation). This discrepancy could lead to an overestimation of monitoring frequency. 
In our study, therapeutic drug monitoring was performed poorly: only in $51 \%$ of cases, TDM was performed as indicated. Shah et al (2014) ${ }^{[21]}$ showed a similar therapeutic drug monitoring rate of $57 \%$ in the group of patients without ID supervision compared to a monitoring rate of $68.3 \%$ in patients with ID supervision. It is important that TDM is performed in these patients, due to the nephrotoxic effects of this group of antibiotics, when administrated in high doses. Intensive TDM offers the possibility to perform dosage adjustment and prevent adverse drug events. In our center, a specialized OPAT-team responsible for the follow-up after discharge is not present.

One of the OPAT quality indicators is frequent laboratory monitoring, as recommended by the IDSA update 2018. In a recent Delphi study, Berrevoets et al.(2019) ${ }^{[22]}$ tried to establish uniform advice for monitoring of laboratory results, which should be executed by the OPAT-team. Berrevoets et al. came to the conclusion that monitoring frequency of OPAT-patients should depend on the agent used, patients condition and comorbidities and duration of OPAT. This is in line with the recommendations of the IDSA guidelines. This study provides additional evidence in the risk factors for readmission in OPAT patients. Our findings emphasize the importance of appropriate monitoring in patients discharged with antimicrobials which require therapeutic drug monitoring. Additionally, introduction of an OPAT-team could lead to appropriate use of antibiotics, as previous studies have shown[11,23], which could help increase antimicrobial stewardship.

This study contributes to understanding of the difficulties of OPAT. We identified independent risk factors in a large cohort of patients discharged with OPAT. These patients signify a respective proportion of the patients with OPAT. The results of our study highlight that OPAT teams should be aware of the higher risk of re-admission in this subgroup of patients. This study could be a great stepping stone for future research and improvement of OPAT-therapy.

Our study had several limitations. First, this study was a retrospective study. Due to the retrospective nature of this study, there remains a possibility that complications were underreported. Our study did give an overview of a large cohort of OPAT patients from 2016 until 2018. Subsequently, we also did not have access to any laboratory results outside of our academic hospital. This could underestimate the adherence to monitoring. An additional uncontrolled factor is the possibility of selection bias.

In conclusion, this study contributes to understanding of the difficulties of OPAT. We identified independent risk factors in patients discharged with OPAT. These patients signify a respective proportion of the patients with OPAT. The results of our study highlight that OPAT teams should be aware of the higher risk of re-admission in this subgroup of patients. The results of this study underscore the need to implement IDSA guidelines and provide OPAT care on the basis of quality indicators, by means of a specialized multidisciplinary team for OPAT.

\section{Future research}

Future research should focus on complications during OPAT and the frequency of monitoring especially TDM. Cost-effectiveness analysis should be integrated in future research in order to provide a solid 
business case for OPAT dedicated teams. Several questions, such as the appropriate quantity of laboratory monitoring, remain undetermined. More research using prospective trials is needed to answer these questions.

\section{Declarations}

\section{FUNDING}

This study was conducted as part of our routine work.

\section{CONFLICTS OF INTEREST}

No conflicts of interest

\section{AVAILABILITY OF DATA AND MATERIAL}

The data that support the findings of this study are available on request from the corresponding author, S. Douiyeb and stored in an anonymized Castor database. The data are not publicly available due to their containing information that could compromise the privacy of research participants.

\section{References}

1. Matthews, P.C., et al., Outpatient parenteral antimicrobial therapy (OPAT): is it safe for selected patients to self-administer at home? A retrospective analysis of a large cohort over 13 years. Journal of Antimicrobial Chemotherapy, 2007. 60(2): p. 356-362.

2. Dalovisio, J.R., et al., Financial impact of a home intravenous antibiotic program on a medicare managed care program. Clin Infect Dis, 2000. 30(4): p. 639-42.

3. Psaltikidis, E.M., et al., Cost-utility analysis of outpatient parenteral antimicrobial therapy (OPAT) in the Brazilian national health system. Expert Rev Pharmacoecon Outcomes Res, 2019. 19(3): p. 341352.

4. Saillen, L., et al., Patient satisfaction in an outpatient parenteral antimicrobial therapy (OPAT) unit practising predominantly self-administration of antibiotics with elastomeric pumps. Eur $\mathrm{J}$ Clin Microbiol Infect Dis, 2017. 36(8): p. 1387-1392.

5. Durojaiye, O.C., et al., Clinical efficacy, cost analysis and patient acceptability of outpatient parenteral antibiotic therapy (OPAT): a decade of Sheffield (UK) OPAT service. Int J Antimicrob Agents, 2018. 51(1): p. 26-32.

6. Allison, G.M., et al., Prediction model for 30-day hospital readmissions among patients discharged receiving outpatient parenteral antibiotic therapy. Clin Infect Dis, 2014. 58(6): p. 812-9.

7. Huang, V., et al., Risk factors for readmission in patients discharged with outpatient parenteral antimicrobial therapy: a retrospective cohort study. BMC Pharmacology and Toxicology, 2018. 19(1): p. 50. 
8. Keller, S.C., et al., Rates of and Risk Factors for Adverse Drug Events in Outpatient Parenteral Antimicrobial Therapy. Clin Infect Dis, 2018. 66(1): p. 11-19.

9. Means, L., et al., Predictors of Hospital Readmission in Patients Receiving Outpatient Parenteral Antimicrobial Therapy. Pharmacotherapy, 2016. 36(8): p. 934-9.

10. Norris, A.H., et al., 2018 Infectious Diseases Society of America Clinical Practice Guideline for the Management of Outpatient Parenteral Antimicrobial Therapy. Clin Infect Dis, 2019. 68(1): p. 1-4.

11. Wijnakker, R., et al., The impact of an infectious disease expert team on outpatient parenteral antimicrobial treatment in the Netherlands. Int J Clin Pharm, 2019. 41(1): p. 49-55.

12. Dryden, M., et al., Antibiotic stewardship and early discharge from hospital: impact of a structured approach to antimicrobial management. J Antimicrob Chemother, 2012. 67(9): p. 2289-96.

13. Mansour, O., J. Heslin, and J.L. Townsend, Impact of the implementation of a nurse-managed outpatient parenteral antibiotic therapy (OPAT) system in Baltimore: a case study demonstrating cost savings and reduction in re-admission rates. J Antimicrob Chemother, 2018. 73(11): p. 3181-3188.

14. Heintz, B.H., J. Halilovic, and C.L. Christensen, Impact of a multidisciplinary team review of potential outpatient parenteral antimicrobial therapy prior to discharge from an academic medical center. Ann Pharmacother, 2011. 45(11): p. 1329-37.

15. Chung, E.K., et al., Development and implementation of a pharmacist-managed outpatient parenteral antimicrobial therapy program. Am J Health Syst Pharm, 2016. 73(1): p. e24-33.

16. Felder, K.K., et al., Risk Factors for Complications during Outpatient Parenteral Antimicrobial Therapy for Adult Orthopedic and Neurosurgical Infections. South Med J, 2016. 109(1): p. 53-60.

17. Duggal, A., W. Barsoum, and S.K. Schmitt, Patients with prosthetic joint infection on IV antibiotics are at high risk for readmission. Clin Orthop Relat Res, 2009. 467(7): p. 1727-31.

18. Shrestha, N., et al., 758: Treatment Complications During Outpatient Parenteral Antimicrobial Therapy (OPAT) Administered at Home. Open Forum Infect Dis, 2014. 1(Suppl 1): p. S214.

19. Hale, C.M., et al., Characterization of Drug-Related Problems Occurring in Patients Receiving Outpatient Antimicrobial Therapy. J Pharm Pract, 2017. 30(6): p. 600-605.

20. Huck, D., et al., Association of laboratory test result availability and rehospitalizations in an outpatient parenteral antimicrobial therapy programme. J Antimicrob Chemother, 2014. 69(1): p. 228-33.

21. Shah, P., et al., Monitoring of Outpatient Parenteral Antimicrobial Therapy and Implementation of Clinical Pharmacy Services at a Community Hospital Infusion Unit. Journal of pharmacy practice, 2014. 28.

22. Berrevoets, M.A.H., et al., Quality indicators for appropriate outpatient parenteral antimicrobial therapy (OPAT) in adults: a systematic review and RAND-modified Delphi procedure. Clin Infect Dis, 2019.

23. Hersh, A.L., et al., Impact of Antimicrobial Stewardship for Pediatric Outpatient Parenteral Antibiotic Therapy. Journal of the Pediatric Infectious Diseases Society, 2017. 7(2): p. e34-e36. 


\section{Tables}

Table 1: Baseline characteristics patients discharged with OPAT 2016-2018 


\begin{tabular}{|c|c|c|c|c|c|}
\hline & & $\begin{array}{l}\text { Total } \\
\text { cohort } \\
(\mathrm{N}=247)\end{array}$ & $\begin{array}{l}\text { Not } \\
\text { Readmitted } \\
(\mathrm{N}=220)\end{array}$ & $\begin{array}{l}\text { Readmitted } \\
\mathrm{N}=27\end{array}$ & $\begin{array}{l}\mathrm{p}- \\
\text { value }\end{array}$ \\
\hline \multirow[t]{2}{*}{ Hospital ward } & Surgical & $\begin{array}{l}109 \\
(44 \%)\end{array}$ & 95 (87\%) & $14(13 \%)$ & 0.417 \\
\hline & Non-surgical & $\begin{array}{l}138 \\
(56 \%)\end{array}$ & $125(91 \%)$ & $13(9 \%)$ & \\
\hline Age (median, IQR) & & $\begin{array}{l}62(50- \\
72)\end{array}$ & $63(50-72)$ & $60(50-72)$ & 0.714 \\
\hline Gender & Male & $\begin{array}{l}159 \\
(64 \%)\end{array}$ & $145(91 \%)$ & $14(9 \%)$ & 0.151 \\
\hline \multirow[t]{12}{*}{$\begin{array}{l}\text { Indication for } \\
\text { OPAT }\end{array}$} & Bone and joint infections & $\begin{array}{l}41 \\
(17 \%)\end{array}$ & $36(88 \%)$ & $5(12 \%)$ & 0.785 \\
\hline & $\begin{array}{l}\text { Prosthetic } \\
\text { infections(orthopedic) }\end{array}$ & $\begin{array}{l}35 \\
(14 \%)\end{array}$ & $25(71 \%)$ & $10(29 \%)$ & $\begin{array}{l}< \\
0.05\end{array}$ \\
\hline & Complicated UTI & $\begin{array}{l}34 \\
(14 \%)\end{array}$ & $32(94 \%)$ & $2(6 \%)$ & 0.551 \\
\hline & Respiratory infections & $\begin{array}{l}32 \\
(13 \%)\end{array}$ & $28(88 \%)$ & $3(12 \%)$ & 0.762 \\
\hline & Vascular (stent) infections & $22(9 \%)$ & 14 & - & 0.144 \\
\hline & Intra-abdominal infection & $18(7 \%)$ & $17(94 \%)$ & $1(6 \%)$ & 0.702 \\
\hline & $\begin{array}{l}\text { Central nervous system } \\
\text { infection }\end{array}$ & $17(7 \%)$ & $15(88 \%)$ & $2(12 \%)$ & 1.000 \\
\hline & Skin and soft tissue infection & $16(7 \%)$ & $14(88 \%)$ & $2(12 \%)$ & 0.689 \\
\hline & Candidemia & $15(6 \%)$ & 15 & - & 0.384 \\
\hline & Endocarditis & $11(4 \%)$ & $9(82 \%)$ & $2(18 \%)$ & 0.343 \\
\hline & $\begin{array}{l}\text { Bacteraemia (unknown focus } \\
\text { of infection) }\end{array}$ & $4(2 \%)$ & 4 & - & 1.000 \\
\hline & Other & $2(1 \%)$ & 2 & - & 1.000 \\
\hline \multirow[t]{4}{*}{$\begin{array}{l}\text { Antimicrobial } \\
\text { therapy }\end{array}$} & Aminoglycosides/vancomycin & $\begin{array}{l}40 \\
(15 \%)\end{array}$ & $28(70 \%)$ & $12(30 \%)$ & 0.000 \\
\hline & Antifungal therapy & $\begin{array}{l}26 \\
(10 \%)\end{array}$ & 26 & - & 0.053 \\
\hline & Carbapenem & $\begin{array}{l}29 \\
(11 \%)\end{array}$ & $28(97 \%)$ & $1(3 \%)$ & 0.331 \\
\hline & Cephalosporin & $\begin{array}{l}68 \\
(26 \%)\end{array}$ & $65(96 \%)$ & $3(4 \%)$ & 0.043 \\
\hline
\end{tabular}




\begin{tabular}{|llllll|} 
& Penicillin & $\begin{array}{l}99 \\
(37 \%)\end{array}$ & $87(88 \%)$ & $12(12 \%)$ & 0.679 \\
\cline { 2 - 5 } & Other & $1(0.4 \%)$ & 1 & \\
\hline $\begin{array}{l}\text { OPAT treatment } \\
\text { duration } \\
\text { (median, IQR) }\end{array}$ & $\begin{array}{l}14(8- \\
32)\end{array}$ & $13(7-32)$ & $27(11-36)$ & 0.097 \\
\hline $\begin{array}{l}\text { Destination } \\
\text { discharge }\end{array}$ & $\begin{array}{l}\text { Nursing facility/rehabilitation } \\
\text { center }\end{array}$ & $\begin{array}{l}28 \\
(11 \%)\end{array}$ & $22(79 \%)$ & $6(21 \%)$ & 0.098 \\
\cline { 2 - 5 } & Home & $\begin{array}{l}219 \\
(89 \%)\end{array}$ & $198(90 \%)$ & $21(10 \%)$ & \\
\hline Type of line & PICC catheter & $\begin{array}{l}207 \\
(84 \%)\end{array}$ & $183(88 \%)$ & $24(12 \%)$ & 0.586 \\
& Other catheter & $\begin{array}{l}40 \\
(17 \%)\end{array}$ & $27(68 \%)$ & $13(32 \%)$ & \\
\hline
\end{tabular}

Table 2. Complications and readmission-rate during OPAT treatment

\begin{tabular}{|llll|}
\hline Complications & $\begin{array}{l}\text { Total } \\
(\mathrm{n}=53)\end{array}$ & $\begin{array}{l}\text { Readmitted } \\
(\mathrm{n}=25)\end{array}$ & $\begin{array}{l}\text { Visit to emergency room } \\
(\mathrm{n}=4)\end{array}$ \\
\hline $\begin{array}{l}\text { Adverse drug events } \\
\text { (ADE) }\end{array}$ & 16 & $4(16 \%)$ & $1(25 \%)$ \\
\hline Catheter related events & 21 & $6(25 \%)$ & $2(50 \%)$ \\
\hline Non-OPAT related & 4 & $4(16 \%)$ & - \\
\hline Treatment failure & 12 & $11(44 \%)$ & $1(25 \%)$ \\
\hline
\end{tabular}

\section{Table 3 is not available with this version}

\section{Figures}




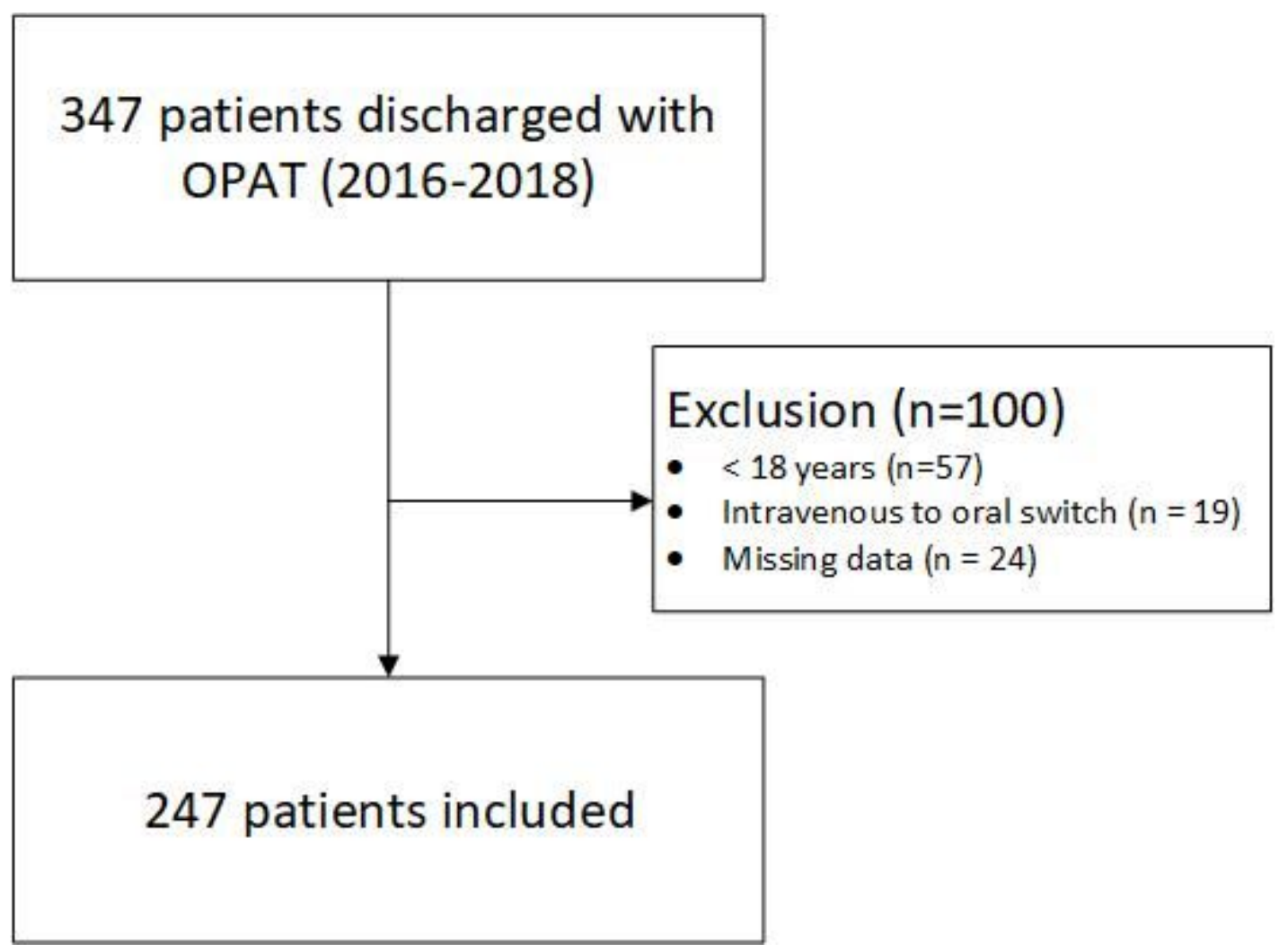

Figure 1

Legend not included with this version

\section{Distribution of bacterial pathogens use in OPAT patients}

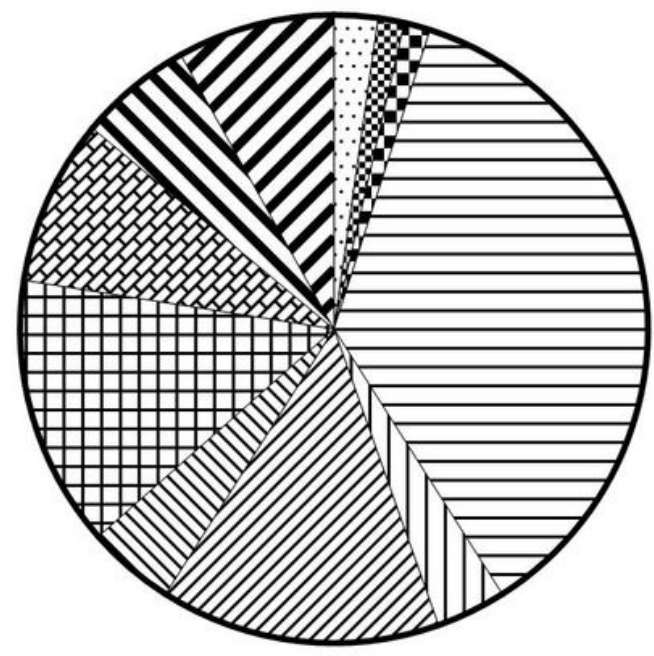

Treponema spp.

Corynebacterium

$\mathbf{m}$ Actinomyces spp.

Ð Staphylococcus spp.

س Klebsiella spp.

moscherichia coli

Enterococcus

Pseudomonas spp

Streptococcus spp

$\boldsymbol{\nabla}$ Culture negative

שa Other

\section{Total $=\mathbf{2 2 2}$}

Figure 2 


\section{Distribution of parenteral antimicrobial therapy}

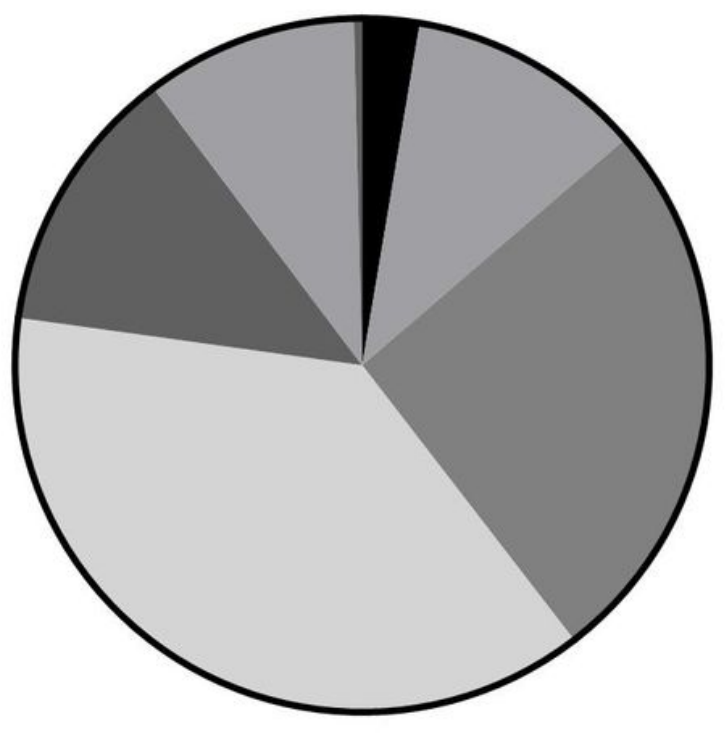

- Aminoglycosiden

$\square$ Carbapenem

$\square$ Cephalosporin

$\square$ Pencillin

$\square$ Vancomycin

$\square$ Anti-fungal therapy

$\square$ Other

\section{Total $=\mathbf{2 6 3}$}

Figure 3

Legend not included with this version 


\section{Complications + readmission}

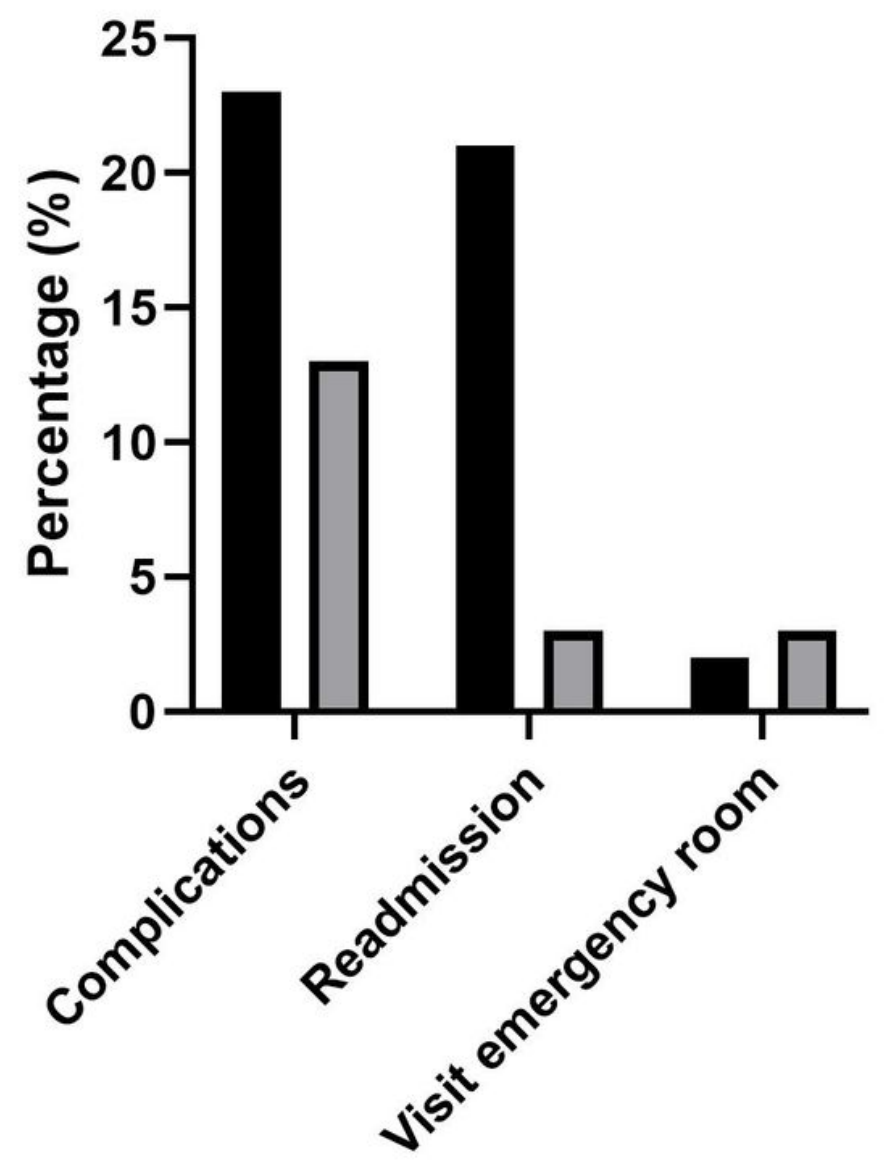

Weekly monitoring $(n=129)$

Don-weekly monitored $(n=61)$

Figure 4

Legend not included with this version

\section{Supplementary Files}

This is a list of supplementary files associated with this preprint. Click to download.

- STROBEchecklistv4combined.docx

- IJCPSubmissionChecklistJuly21U.docx 